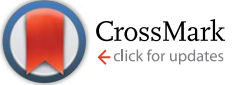

Cite this: RSC Adv., 2016, 6, 79723

\title{
Occurrence of earthy-musty taste and odors in the Taihu Lake, China: spatial and seasonal patterns $\dagger$
}

Received 29th June 2016

Accepted 8th August 2016

DOI: 10.1039/c6ra16733k

www.rsc.org/advances

\author{
Yingchao Zhang, ${ }^{a}$ Ni Zhang, ${ }^{b}$ Bingbing $X u^{* c}$ Jolanta Kumirska ${ }^{d}$ and Fei Qi ${ }^{* b}$
}

In recent years, the increasing eutrophication of large freshwater lakes in China has resulted in significant algal blooms. The serious taste and odor (T\&O) problems that raised from algal blooms have been widely studied. To supplement these studies, the types and concentrations of natural earthy-musty T\&O compounds in the Taihu Lake were studied in September 2009, January 2010 and September 2010. In the first sampling period, $\beta$-ionone and $\beta$-cyclocitral were the major odorants, which changed to 2isopropyl-3-methoxypyrazine (IPMP) and 2-isobutyl-3-methoxypyrazine (IBMP) in September 2010. The occurrence of T\&Os was more significant in September (Autumn) than in January (Winter) in both the Zhushan Lake and Meiliang Bay, which are two important regions of the Taihu Lake. However, other regions showed more serious occurrence of T\&Os, such as West Coast and South Coast, which was first reported based on the whole lake survey. The concentration of T\&Os in the Zhushan Lake was much higher than that in the Meiliang Bay in both January 2010 and September 2010. The reason for the T\&O occurrence is suggested by multivariate statistical methods, including principal component analysis and cluster analysis. It is confirmed that the T\&O occurrence is more serious in the Taihu Lake due to unaccepted chemicals compared with other eutrophication lakes in China. The initial origins of T\&O in the Taihu Lake are also confirmed, and several suggestions on how to control the earthy-musty T\&O in lakes or drinking water treatment plants are provided.

\section{Introduction}

Increasing eutrophication has led to frequent outbreaks of cyanobacterial blooms in many lakes around the world in recent decades. ${ }^{1-3}$ Cyanobacteria produce metabolites, such as algae toxins and/or taste and odor (T\&O) compounds, which impact water supplies. T\&O compounds in natural waters have also been reported throughout the world, ${ }^{4,5}$ which have caused great economic losses to the aquaculture and fisheries industries. In general, the typical natural T\&O compounds derived from algae or other microorganisms are 2-methylisoborneol (2-MIB), geosmin, 2-isopropyl-3-methoxypyrazine (IPMP) and 2-isobutyl-3methoxypyrazine (IBMP), and these cause an earthy and musty odor. Although $\beta$-cyclocitral and $\beta$-ionone are also

${ }^{a}$ State Key Laboratory of Automotive Simulation and Control, Jilin University, Changchun 130022, China

${ }^{b}$ State Key Laboratory of Environmental Criteria and Risk Assessment, Chinese Research Academy of Environmental Sciences, Beijing 100012, China. E-mail: qifei@ bjfu.edu.cn; qifei_hit@163.com; Fax: +86 10 62336596; Tel: +86 1062336615

'Beijing Key Laboratory for Source Control Technology of Water Pollution, College of Environmental Science and Engineering, Beijing Forestry University, Beijing 100083, China. E-mail:xbb_hit@126.com

${ }^{d}$ Department of Environmental Analysis, Faculty of Chemistry, University of Gdansk, Wita Stwosza 63, 80-308, Poland

$\dagger$ Electronic supplementary information (ESI) available. See DOI: $10.1039 / \mathrm{c} 6 \mathrm{ra} 16733 \mathrm{k}$ generated from algae, they create woody/violet/tobacco/flowery odors in water containing algal bloom. ${ }^{4}$ It is important that consumers complain about drinking water quality and the rising cost of drinking water treatment to improve it. Until 2000, only the mutagenic activity of T\&O compounds, such as 2-MIB and geosmin, was reported using the Ames test, which showed a negative result to exposed Salmonella typhimurium tester strains. ${ }^{6}$ However, in recent years, more research has focused on the cytotoxicity or genotoxicity of geosmin/2-MIB to humans using HepG2 cells, ${ }^{7}$ Chinese hamster ovary cells, ${ }^{8}$ and mammalian cells ${ }^{9}$ as probes. Results have shown that only exposure to a high concentration of geosmin/2-MIB (30-100 $\left.\mathrm{mg} \mathrm{L} \mathrm{L}^{-1}\right)$ is cytotoxic or genotoxic to humans; $;^{7-9}$ however, the presence of geosmin in water is associated with enhanced DNA damage after long exposure time. ${ }^{8}$ Therefore, it is very important to survey the occurrence of T\&O compounds in surface water and explore novel and efficient drinking water treatment technologies.

In recent years, the $\mathrm{T} \& \mathrm{O}$ problems in some lakes in China have become more serious, and there have been several outbreaks of T\&O in China since $2000 .^{5}$ These problems are generally more serious in the late summer or early autumn in the Dianchi Lake and Taihu Lake. ${ }^{7}$ The most famous event is the algal bloom in the Taihu Lake, which affected the drinking water quality in Wuxi city in 2007. ${ }^{10}$ In the Taihu Lake, eutrophication and cyanobacteria blooms are particularly serious 
and cyanobacterial blooms occur for more than 3-4 months each year. The bloom may even last all year in the north and central parts and on the west coast of the Taihu Lake. ${ }^{11-13}$ The spatial and seasonal patterns of $\mathrm{T} \& \mathrm{O}$ in the Gonghu Bay region of the Taihu Lake have been studied previously; ${ }^{\mathbf{1 1}, \mathbf{1 4}}$ however, the studies were limited to a small zone in the Taihu Lake and focused on organic sulfur compounds that were generated from residual algal cell decay and sediment deterioration. ${ }^{15-17}$ Therefore, a detailed investigation of the T\&O occurrence in the Taihu Lake is important to provide scientific data for lake management and water purification. In the present investigation, the spatial pattern of T\&O over all regions of the Taihu is explored in detail to give an overview of T\&O in the Taihu Lake. This development provides important scientific data on the conventional earthy-musty T\&Os, a topic that has received attention elsewhere in the world but is poorly studied in China. Based on this, lake management/utilization and water quality remediation could be done more efficiently. Temporal variations of $\mathrm{T} \& \mathrm{O}$ occurrence seem significant different among different surface water around the world, due to the variation in geographical location, climate, hydraulic characteristics, water quality, and aquatic ecology. Thus, only important season samples (winter and autumn) were collected herein to discuss the season/temperature effect on T\&O occurrence. Finally, the relationship between $\mathrm{T} \& \mathrm{O}$ compounds and water quality parameters is clarified by multivariate statistical methods and the initial source of T\&O is also proposed. The results obtained from the abovementioned content are very important for lake water management, including limiting the concentration of $\mathrm{T} \& \mathrm{O}$ as a water quality criterion, suggesting analysis/monitoring methods and source control, and water purification in situ and in drinking water treatment plants.

\section{Methodology}

\section{Chemicals}

Standards of six target T\&O compounds (2-MIB, geosmin, IPMP, IBMP, $\beta$-ionone and $\beta$-cyclocitral) in methanol were purchased from Sigma-Aldrich (USA). Sodium chloride (purchased from Sigma-Aldrich, USA) used in the T\&O extraction process was reagent grade and was calcinated at $450{ }^{\circ} \mathrm{C}$ in a muffle oven for further use. The other chemicals used in this study were analytical reagents or higher grades without any purification.

\section{Sample site and collection}

Taihu Lake $\left(30^{\circ} 56^{\prime}-31^{\circ} 33^{\prime} \mathrm{N}, 119^{\circ} 54^{\prime}-120^{\circ} 36^{\prime} \mathrm{E}\right)$, which is the third largest freshwater lake in China, is located in the eastern part of the country. Many earlier publications indicate that samples collected in January show a lower T\&O concentration; however, the dead algal cells release T\&O compounds during the hibernation period, thus samples collected in September show the highest concentrations in the Taihu Lake, ${ }^{17}$ Chaohu Lake $^{\mathbf{1 8}}$ and Beijing Miyun Reservoir. ${ }^{19}$ Therefore, 40 sampling sites over the entire Taihu Lake were selected in September 2009 and 2010. The sites are shown in Fig. 1 and their coordinates in Table S1. $\dagger$ In January 2010, 20 sampling sites were taken in the

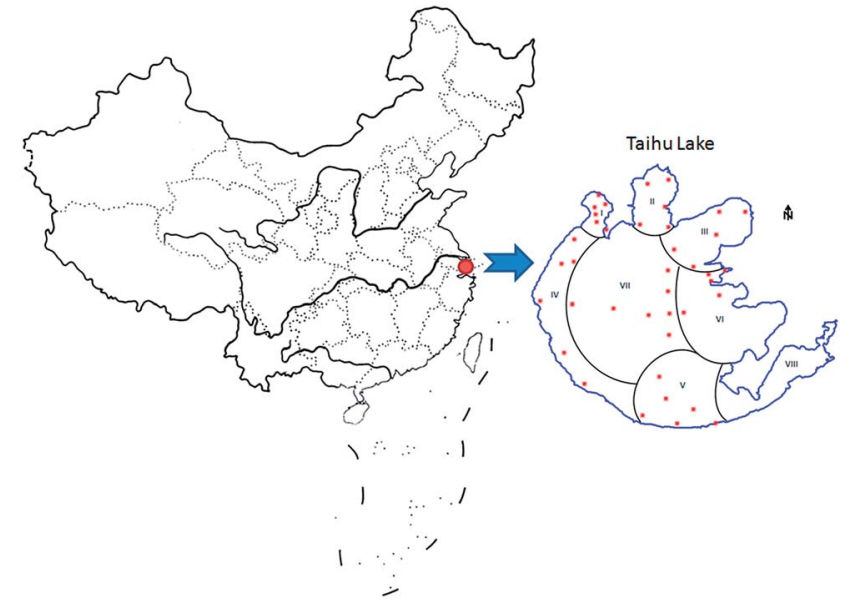

Fig. 1 Schematic of the sampling site in the Taihu Lake, China.

Zhushan Lake (I) and Meiliang Bay (II), as shown in Table S1, $\dagger$ to study the effect of the season. All samples in this study were collected in the abovementioned timeframe. Each integrated water sample is a mixture of three subsamples, which were collected $0.5 \mathrm{~m}$ below the surface. Four water samples were collected in 1.0 L narrow-necked glass bottles leaving no headspace for one site, in which the average of concentration is shown. $\mathrm{NaN}_{3}$ and hydroxylamine hydrochloride were added to two of the bottles to avoid the growth of microorganisms, and then the samples were stored immediately in a portable refrigerator at approximately $4{ }^{\circ} \mathrm{C}$ until the T\&O compounds could be analyzed.

\section{Water quality parameters analysis}

Water samples without $\mathrm{NaN}_{3}$ and hydroxylamine hydrochloride added were filtered through $0.45 \mu \mathrm{m}$ fiberglass filters (Whatman GF-C) before the water quality parameters analysis. Total phosphorus (TP) was measured by colorimetry after digestion with $\mathrm{H}_{2} \mathrm{SO}_{4}{ }^{20}$ Total nitrogen (TN) and total organic carbon (TOC) were determined on a TC/TN analyzer (Multi N/C 3100, analytic Jena, Germany) using the catalytic combustion method. Chlorophyll-a (Chl-a) was determined spectrophotometrically according to Lorenzen. ${ }^{15}$ After filtration on fiberglass filters, chlorophyll-a in the sample was extracted for $24 \mathrm{~h}$ in $90 \%$ acetone. Ammonia was determined by the sodium reagent method. Nitrate and sulfate were determined via ion chromatography (ICS-3000, Dionex, USA). Table S2† summarizes the characteristics of the basic water parameters in the main zones of the Taihu Lake after duplicate sampling.

\section{Sample preparation and analysis for dissolved T\&O compounds}

Similar to previous investigations, ${ }^{5,14,21}$ dissolved T\&O compounds are the main contributors and direct dominant factors for the negative aesthetic style of the lake water, rather than particle T\&O compounds that are potential contributors of the water aesthetic and more significantly influence the efficiency of drinking water treatment plants. Therefore, only 
Table 1 Features for the analysis method and QA/QC of each T\&O compound

\begin{tabular}{|c|c|c|c|c|c|}
\hline T\&O compound & Retention time (min) & $m / z$ value selected & $\operatorname{RSD}^{b}(\%)$ & Detection $\operatorname{limit}^{c}\left(\mathrm{ng} \mathrm{L}^{-1}\right)$ & Odor of threshold concentration $\left(\mathrm{ng} \mathrm{L}^{-1}\right)$ \\
\hline IPMP & 11.758 & $137^{a}, 152$ & 1.77 & 0.70 & 20.0 (ref. 15) \\
\hline$\beta$-Cyclocitral & 12.325 & $131^{a}, 132$ & 4.38 & 0.40 & 22.0 (ref. 22) \\
\hline 2-MIB & 13.127 & $95^{a}, 107$ & 2.08 & 0.40 & 15.0 (ref. 15) \\
\hline Geosmin & 16.633 & $112^{a}, 41$ & 8.97 & 0.50 & 4.0 (ref. 15) \\
\hline$\beta$-Ionone & 17.654 & $177^{a}, 92$ & 1.85 & 0.50 & 7.0 (ref. 15 and 23 ) \\
\hline
\end{tabular}

dissolved T\&Os were analyzed in this study to evaluate the water off-flavor aesthetic. A $50 \mathrm{~mL}$ water sample was filtered through a fiberglass filter $(0.45 \mu \mathrm{m})$ under a low vacuum and the filtrate was analyzed for dissolved T\&O compounds. PDMS/DVB/CAB fibre (Supelco, USA) was chosen for solid-phase microextraction (SPME) extraction. ${ }^{15}$ Briefly, $\mathrm{NaCl}$ (3.0 g) was added to the water samples. The vial was controlled at a temperature of $65{ }^{\circ} \mathrm{C}$ using a water jacketed system, after $\mathrm{NaCl}$ was dissolved. Furthermore, the fibre was injected through a silicon-Teflon coated septum and placed into the headspace of a $40 \mathrm{~mL}$ extraction vial with $20 \mathrm{~mL}$ of water sample. The extraction time was controlled at 30 min under mixing. GC-MS analysis was performed for the identification and quantitation of T\&O compounds. A $30 \mathrm{~m} \mathrm{HP-17MS} \mathrm{(i.d.} 0.25 \mathrm{~mm}$, coating film thickness $0.25 \mu \mathrm{m}$ ) capillary column was used. After the SPME extraction process, the fibre was introduced directly into the injector $\left(250^{\circ} \mathrm{C}\right)$ after $10 \mathrm{~min}$ exposure time. The GC temperature program was set at $45{ }^{\circ} \mathrm{C}$ for $4 \mathrm{~min}$, increased to $240{ }^{\circ} \mathrm{C}$ at $10^{\circ} \mathrm{C} \mathrm{m^{-1 }}$ and kept for $1 \mathrm{~min}$, and then increased to 280 at 10 ${ }^{\circ} \mathrm{C} \mathrm{min}^{-1}$ and held for $4 \mathrm{~min}$. The transfer-line temperature was $280{ }^{\circ} \mathrm{C}$. The quadrupole mass spectrometer was operated in the EI positive mode $(70 \mathrm{eV})$. For qualitative analysis, the full scan mode from 50 to $400 \mathrm{~m} / \mathrm{z}$ was used for the primary identification of T\&O compounds according to the NIST database. The selected ions monitor (SIM) mode was selected for quantitative analysis of six T\&O compounds. Table 1 shows detail information on the SIM parameters and QA/QC of this method for each T\&O compound.

\section{Statistical analysis}

Pearson correlation analysis was conducted to determine the relationship between T\&O compound concentrations and water quality parameters. Principal component analysis (PCA) and cluster analysis (CA) were used to analyze the origin of T\&O. All statistical analyses were carried out using SPSS ${ }^{\circ}$ for Windows (Version 17.0; SPSS, Chicago, IL, USA).

\section{Results and discussion}

\section{Characteristics of the earthy-musty taste and odor in the Taihu Lake}

In this study, first, the T\&O occurrence in the Taihu Lake in September 2009 and 2010 was studied (Fig. 2(A) and (B)) as many results report peak concentrations of $\mathrm{T} \& \mathrm{O}$ in this month. ${ }^{17-19}$ In September 2009, the concentration of $\beta$-ionone (58.62-1932.73 $\mathrm{ng} \mathrm{\textrm {L } ^ { - 1 }}$ ) was the highest among all the investigated T\&O compounds, which is a major off-flavor metabolite of $M$. aeruginos $a^{\mathbf{1 5 2 4}}$ and a product of carotene (also an important metabolite of Microcystis aeruginosa) oxidation when it is exposed to oxygen gas. ${ }^{25}$ An earlier study also identified it as a T\&O compound in lake water. Algae, C. caldarium, ${ }^{26}$ S. uvella, ${ }^{26}$ S. subspicatus, ${ }^{27}$ P. autumnale ${ }^{28}$ and red cyanobacterium $(P$. rubescens) ${ }^{29}$ are the main producers of $\beta$-ionone; however, only $M$. aeruginosa is the dominating species in the Taihu Lake. ${ }^{30}$ Similar producers and generation pathways were found for $\beta$ cyclocitral, which contribute to the blue color formed in the natural environment with the lysis of cyanobacteria and play a key role in the life of Microcystis. ${ }^{31}$ In addition, green algae $(C$. fulvescens) and brown algae (C. costata and A. crassifolia) form $\beta$ cyclocitral, which was not detected in the Taihu Lake. ${ }^{32}$ The second highest was IBMP with a concentration range of 58.64$219.14 \mathrm{ng} \mathrm{L^{-1 }}$. IBMP and IPMP have been identified in natural waters as musty $\mathrm{T} \& \mathrm{O}$ compounds, where they are reported to be formed from microbial degradation of grass under anaerobic conditions $^{29}$ and metabolites of soil organisms such as actinomycetes ${ }^{33,34}$ and A. Formosa. ${ }^{27}$ Therefore, the presence of actinomycetes and sediment disturbance lead to the occurrence of IBMP and IPMP, since no other precursors were identified in the Taihu Lake from the literature. The concentrations of 2-MIB and geosmin were much lower than that of other odorants in both September 2009 and September 2010, which is in agreement with previously published results. ${ }^{15}$ 2-MIB and geosmin are the most conventional earthy-musty $\mathrm{T} \& \mathrm{O}$ compounds and were reported very earlier from over fifty cyanobacterial species, ${ }^{35}$ including Anabaena, Nostoc, Lyngbya, Oscillatoria, Phormidium, ${ }^{28}$ Planktothrix, ${ }^{\mathbf{3 6}}$ Pseudanabaena, Aphanizomenon and actinomycetes, but they are not the main algae species contributors in the Taihu Lake. In September 2009, the concentration order of T\&O compounds was as follows: $\beta$-ionone $>$ IBMP $>$ IPMP $>\beta$-cyclocitral $>$ geosmin $>2$-MIB. In September 2010, the concentrations of T\&O were obviously much higher than in September 2009. The major odorants were IPMP and IBMP, with concentration ranges of 19.31-10 156.37

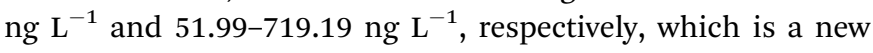
result based on a literature review. The concentration ranges of $\beta$-ionone and $\beta$-cyclocitral were 4.66-124.59 $\mathrm{ng} \mathrm{\textrm {L } ^ { - 1 }}$ and 9.5- 

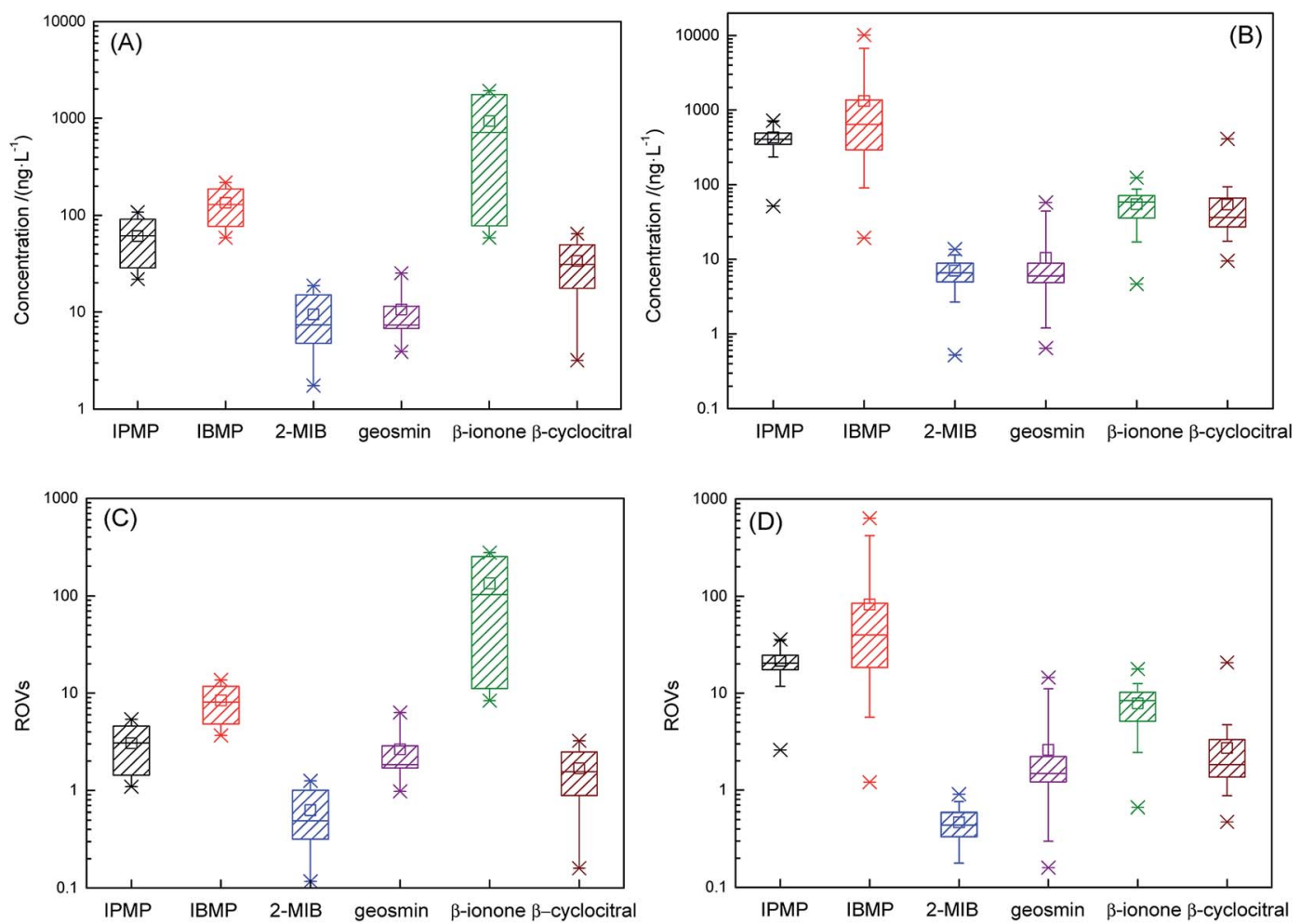

Fig. 2 Occurrence characteristics of T\&O in the Taihu Lake, (A) occurrence in September 2009; (B) occurrence in September 2010; (C) ROVs in September 2009; and (D) ROVs in September 2010.

$414.96 \mathrm{ng} \mathrm{L}^{-1}$, respectively, in September 2010. In contrast to 2009 , the concentration order of T\&O compounds in September 2010 was IBMP $>$ IPMP $>\beta$-ionone $>\beta$-cyclocitral $>$ geosmin $>2$ MIB. The observed differences in the occurrence of T\&O in 2009 and 2010 suggest a change in the producer of T\&O compounds. Based on the abovementioned analysis, the reason for the occurrence of IBMP and IPMP might be the presence of actinomycetes, other soil microorganisms and sediment disturbance in the lake; however, the quite low concentration of 2-MIB and geosmin in this study confirms that less actinomycetes were present in the Taihu Lake. Therefore, soil microorganisms in sediment, the disturbance of sediment and hydraulics contributed the presence of IBMP and IPMP in 2010. Moreover, inadequate studies of T\&O in Taihu Lake were performed in 2010 and only a specific region was focused previously. The serious occurrence of IBMP and IPMP here is a result based on the whole lake survey. In previous studies, $\beta$-ionone and $\beta$ cyclocitral were also identified as major odorants in the Taihu Lake, with maximum concentrations of $50.44 \mathrm{ng} \mathrm{L}^{-1}$ and 537.61 ng $\mathrm{L}^{-1}$, respectively. ${ }^{15}$ In Chen's study, it was concluded that $M$. aeruginosa was the dominant alga and $\mathrm{T} \& \mathrm{O}$ producer in the Taihu Lake..$^{37,38}$

Table 2 shows a summary of earthy-musty T\&O occurrences in China, including the Taihu Lake and other sites all over this country. According to these data, earthy-musty T\&Os focus on 2-MIB, and this appears most frequently in the studies. Lake waters experience more serious T\&O loading than rivers (Table 2); moreover, the Taihu Lake was characterized with the highest concentration of T\&O, even though samples were collected at different sites and times. Although the Chaohu Lake showed a similar eutrophication status to the Taihu Lake, the concentration of T\&O was much lower than that in the Taihu Lake and the dominant T\&O was geosmin. Compounds including $\beta$-ionone and $\beta$-cyclocitral were dominant in the Taihu Lake, and this is in agreement with the results obtained for 2009 in this study. However, higher concentrations of IPMP and IBMP were observed in the samples collected in 2010 in this study, which were not reported previously and form an important supplement to the Taihu Lake's scientific T\&O data.

The odor of threshold concentration (OTC) is an important parameter for characterizing T\&O compounds. If the concentration of T\&O compounds exceeds the OTC, T\&Os could be perceived by humans. Different T\&O compounds exhibit different OTCs, as shown in Table 1 . The relative odor values (ROVs), which are calculated using ([detected concentration] [threshold value])/([threshold value]), were considered first in D. Sedlak' group ${ }^{23}$ but were ignored in the published results in China. If the ROV is greater than zero, humans can smell or taste the T\&O compounds. It is obvious from Fig. 2(C) and (D) that all the $\mathrm{T} \& \mathrm{O}$ compounds studied here show higher concentrations than their own OTCs in both 2009 and 2010, expect for 2-MIB. In September 2009, the ROVs for $\beta$-ionone were the highest among the six types of T\&O compounds and ranged from 8.37 to 276.10. Comparably, $\beta$-cyclocitral, showed a lower ROV. The ROVs for $\beta$-ionone and $\beta$-cyclocitral in September 2010 were lower than those in September 2009. The ROV of IBMP, ranged from 3.66 to 13.70 in September 2009, and 
Table 2 Published data on the occurrence of earthy-musty T\&Os in the surface waters of China

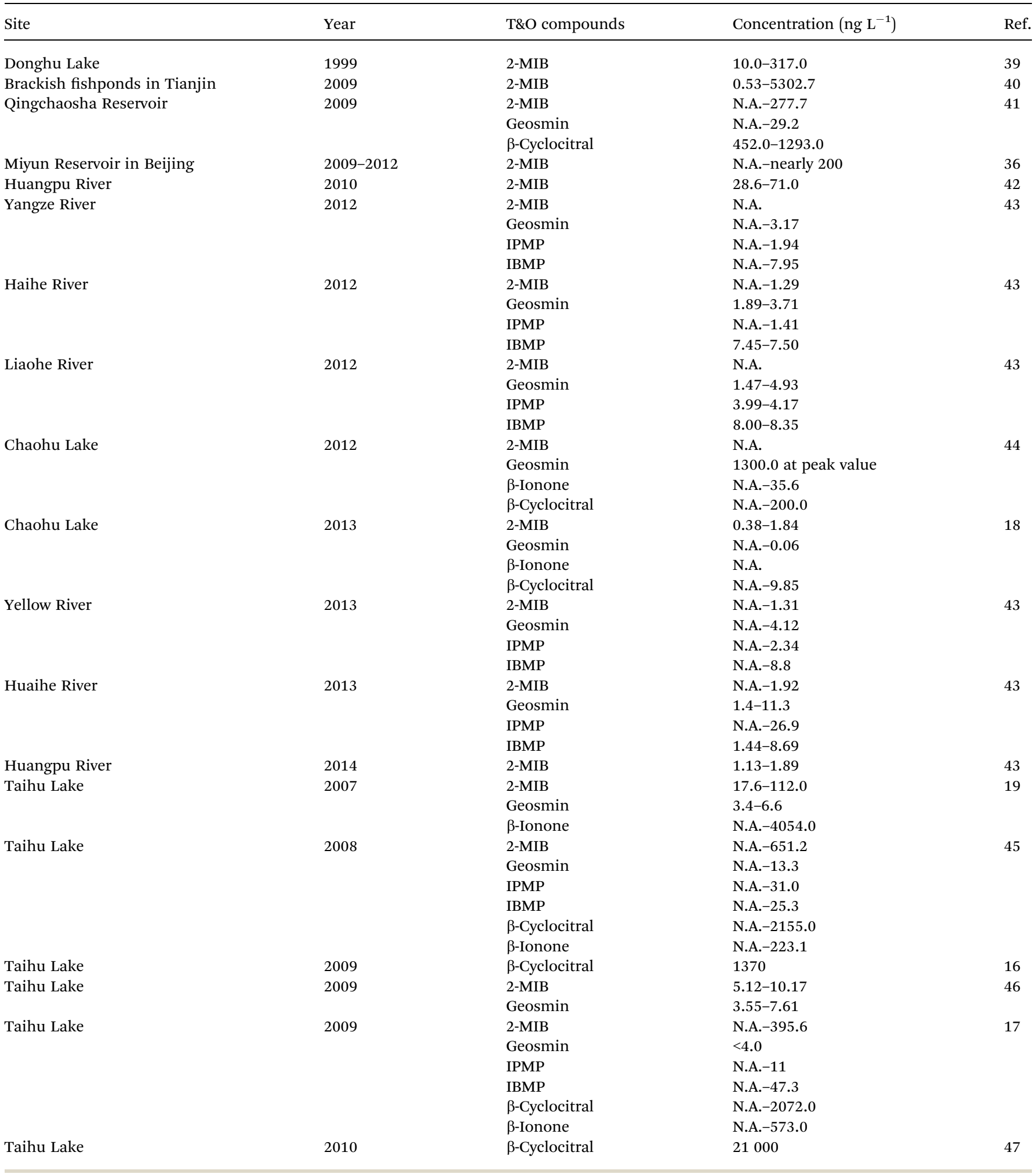

increased to become the most serious T\&O compound. The ROVs of IBMP and IPMP were much higher in September 2010 than in September 2009. The patterns between the concentrations and the ROVs were very similar, because most samples showed higher concentrations than their OTCs.
Based on the results from 2009 and 2010, the major T\&O pollutants in the Taihu Lake were $\beta$-ionone and $\beta$-cyclocitral as metabolites of M. aeruginosa and IPMP and IBMP, which might be formed by soil organics and released by sediment disturbance and hydraulics in the Taihu Lake. In general, odorants 
such as 2-MIB and geosmin did not dominate in the Taihu Lake. The concentrations of IPMP and IBMP increased from September 2009 to September 2010 and the concentration of $\beta$ ionone decreased during this period, which indicated that the drivers of the $\mathrm{T} \& \mathrm{O}$ generation can change during this time.

\section{Characteristics of T\&O in special regions of the Taihu Lake}

To grasp the T\&O exposure characteristics over the entire lake, eight zones (Zhushan Lake (I), Meiliang Bay (II), Gonghu Lake (III), West Coast (IV), South Lakes (V), East Coast (VI) and Lake Centre (VII)) were identified (Table $\mathrm{S} 1 \dagger$ ) according to their utility functions of agriculture, fishing and drinking water. The samples collected in this study were distributed over seven zones (Table $\mathrm{S} 2 \dagger$ ). The T\&O occurrence in each zone is shown in Fig. 3(A) and (B). In September 2009, the $\beta$-ionone concentration was the highest in the Gonghu Lake (III), West Coast (IV), East Coast (VI) and Lake Center (VII). The concentration of IBMP was the highest in the Zhushan Lake (I), Meiliang Bay (II) and South Lake (V). Moreover, the concentration of IBMP was not as high as that of $\beta$-ionone in these regions, which indicates that different producers or microorganisms dominated in variable zones and utility functions/hydraulics might be the main reason for this. In September 2010, IBMP was the highest in the Gonghu Lake (III), West Coast (IV), South Lake (V), East Coast (VI) and Lake Center (VII). In both the Zhushan Lake (I) and Meiliang Bay (II), IPMP and IBMP were the main T\&O compounds, and their concentrations were similar.
In Fig. 3(C) and (D), the characteristics of the ROVs in each region of the Taihu Lake can be seen. In both 2009 and 2010, the West Coast (IV) exhibited the most serious T\&O pollution, which has not been reported before. IPMP, IBMP and $\beta$-ionone were the major contributors in this area. In September 2009, the order of the ROVs was West Coast $>$ South Coast $>$ East Coast $>$ Lake Center $>$ Gonghu Lake $>$ Meiliang Bay $>$ Zhushan Lake. In September 2010, the ROVs of the T\&O in each region were higher than in 2009. IBMP and IPMP were the major odorants, as in September 2009 but $\beta$-ionone was not the main one. In September 2010, the order of the ROVs was West Coast $>$ East Coast $>$ Lake Center $>$ Gonghu Lake $>$ Meiliang Bay $>$ Zhushan Lake $>$ South Coast. The Taihu Lake, Gonghu Lake, Meiliang Bay and Zhushan Lake were hotspots for algal bloom and eutrophication. Xie's group reported the occurrence of T\&O in the Gonghu zone in 2008 (ref. 15) and 2009. ${ }^{16}$ Their results showed that $\beta$-ionone $\left(<40 \mathrm{ng} \mathrm{L}^{-1}\right)$ and $\beta$-cyclocitral $\left(<300 \mathrm{ng} \mathrm{L}^{-1}\right)$ were the dominant pollutants in 2008 , which is in agreement with this study. However, in our study, the measured concentration of $\beta$-ionone is higher than $\beta$-cyclocitral, which is different from their report. In Xie's report of $2009,{ }^{16}$ the measured concentration of $\beta$-cyclocitral was almost as the same as the value presented in this study. However, the ROVs in the Gonghu Lake, Meiliang Bay and Zhushan Lake were not the highest, as shown in this study. This is the first report using ROVs as evaluation parameters. The interesting West Coast zone results merit attention for future deep study.
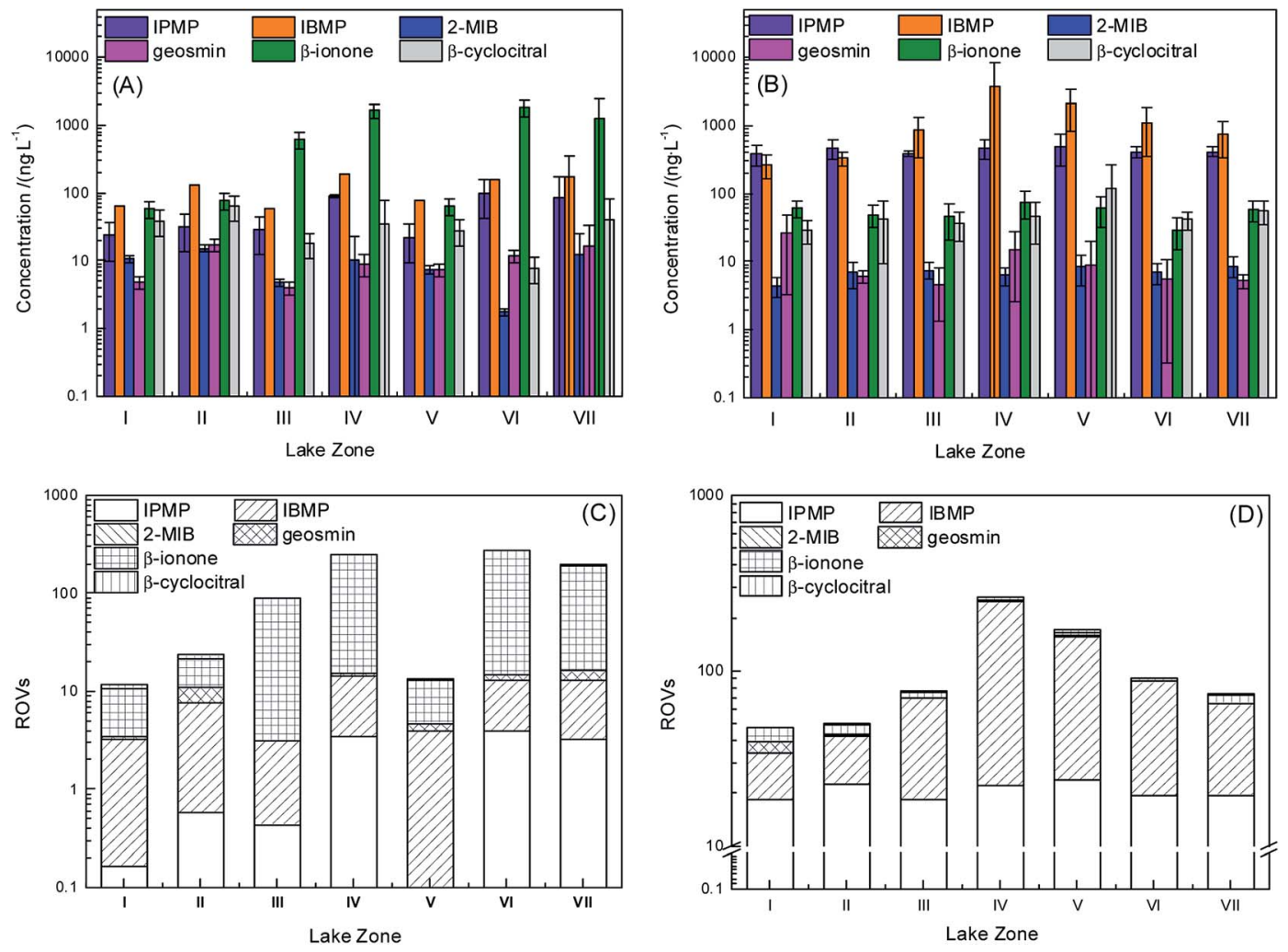

Fig. 3 Occurrence characteristics of T\&O in special regions of the Taihu Lake, (A) occurrence in September 2009; (B) occurrence in September 2010; (C) ROVs in September 2009; and (D) ROVs in September 2010. 


\section{Characteristics of T\&O in the Zhushan Lake and Meiliang Bay}

The Zhuanshan Lake and Meiliang Bay are the main industrial and agricultural regions in the Taihu Lake. Algal blooms occur frequently in these two regions, which show more significant eutrophication and worse water quality. ${ }^{4-50}$ Many researchers have studied the occurrence of algal blooms and phycotoxins in the Zhuanshan Lake and Meiliang Bay; however, few publications have shown T\&O results from these two zones. ${ }^{50}$ Fig. 4 shows the T\&O occurrence characteristics in the Zhushan Lake and Meiliang Bay in winter (January 2010) and autumn (September 2010). In the Meiliang Bay, the dominant T\&O compounds (IPMP, IBMP, $\beta$-ionone and $\beta$-cyclocitral) showed higher concentrations in the samples collected in September. The same results reflect the exposure concentration of T\&O in winter, which were lower than that reported for other seasons in different lakes or surface water. $^{16,39}$ 2-MIB and geosmin as the non-mainstream T\&Os showed less variation. Yu et al. reported an in situ study of T\&O formation from the black bloom of cyanobacteria in the Meiliang Bay in $2014 .{ }^{50}$ According to them, the concentrations of $\beta$-ionone and $\beta$-cyclocitral depending on the cyanobacterial biomass weight are in the range of $200-2100 \mathrm{ng} \mathrm{L}^{-1}$ and 6600$144600 \mathrm{ng} \mathrm{L}^{-1}$, respectively. ${ }^{50}$ The simulated study showed much
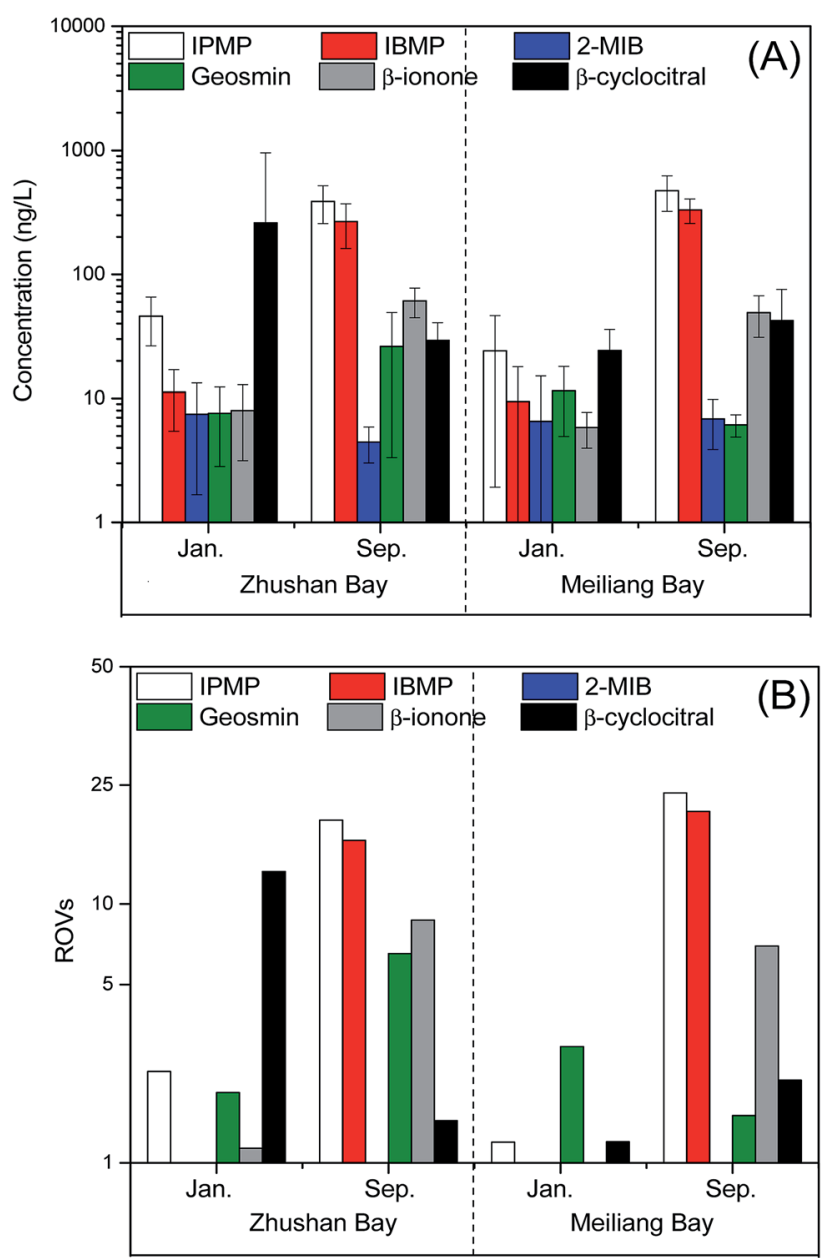

Fig. 4 Comparison of T\&O in the Zhushan Lake and Meiliang Bay, (A) occurrence of T\&O; and (B) ROVs. higher concentrations of $\beta$-ionone and $\beta$-cyclocitral than the measured concentrations in this study. Our samples collected in the Zhushan Lake showed similar results except for $\beta$-cyclocitral. The samples collected in January showed higher concentrations of $\beta$-cyclocitral (260.31 $\mathrm{ng} \mathrm{\textrm {L } ^ { - 1 }}$ ) than that in September (29.33 $\mathrm{ng} \mathrm{\textrm {L } ^ { - 1 }}$ ). This could be explained by algal cell decay or sediment decomposition forming $\beta$-cyclocitral. ${ }^{16}$ According to the literature, ${ }^{22}$ dead Microcystis cells release more carotene that could be oxidized rapidly by oxygen to form high amounts of $\beta$ cyclocitral. In this study, we did not observe that other T\&O compounds showed higher concentrations in winter than in autumn. This means that the decay of algal cells and sediment did not influence their formation during the sampling periods. ${ }^{\mathbf{1 6}}$ The ROVs for all the investigated samples were over zero, which indicated more serious $\mathrm{T} \& \mathrm{O}$ occurrence in both regions. In winter, the ROVs for the Zhushan Lake were more significant than for the Meiliang Bay. The main contributors were IPMP, IBMP and $\beta$-cyclocitral. In autumn, the ROVs in these two regions were at the same level.

\section{Correlation analysis between T\&O occurrence and water quality parameters}

To investigate the correlation between the concentration of $\mathrm{T} \& \mathrm{O}$ and water quality parameters, Pearson correlation analysis was carried out (Table 3). There was a significant negative correlation between geosmin and dissolved oxygen (DO). In general, a higher concentration of nutrient salts can lead to the faster growth of algae and results in a low concentration of DO. ${ }^{49} \mathrm{It}$ was suggested that the geosmin content was negatively related to the amount of algae and concentration of nutrient salts in the Taihu Lake. This result also confirmed that geosmin was not the dominant T\&O compound here. In Table 3, geosmin is seen to have exhibited a significant positive correlation with total nitrogen (TN) concentration and a positive correlation with nitrate $\left(\mathrm{NO}_{3}-\mathrm{N}\right)$ concentration, thus confirming that $\mathrm{TN}$, particularly for nitrate, is a limited factor for the growth of microorganisms/algae (which are potential producers of geosmin in the Taihu Lake). The same statistical relationship was also reported by Xie's group. ${ }^{15}$ Ma et al. reported the positive correlation of geosmin and total phosphate (TP), ${ }^{17}$ which was not observed in this study. The significant negative correlation between DO and $\beta$-ionone/ $\beta$-cyclocitral has been reported before. ${ }^{15}$ The reason for this is the same as the discussion on geosmin and DO. In general, phosphorus is an important nutrient factor for algae growth. ${ }^{18}$ As a result of algal growth, the TP concentration decreases and chlorophyll-a increases. In this study, both IPMP and IBMP showed a negative correlation with TP, which indicates that TP is the limiting factor for IPMP/IBMP formation. This correlation was also reported between IPMP and $\mathrm{TP},{ }^{15}$ but was not found for IBMP. Moreover, a positive correlation between IBMP and chlorophyll-a was observed, which confirms that the source of IBMP is related to phytoplankton. In general, actinomycetes, which are a type of phytoplankton producer, were not the dominant here. Therefore, deep analysis for the source of IBMP should be done in future studies. The dissolved organic carbon (DOC) 
Table 3 Correlation coefficients of different water quality parameters with T\&O in the Taihu Lake

\begin{tabular}{|c|c|c|c|c|c|c|}
\hline Pearson coef. & 2-MIB & Geosmin & $\beta$-Ionone & IPMP & IBMP & $\beta$-Cyclocitral \\
\hline DO & 0.148 & $-0.571^{b}$ & -0.068 & 0.098 & 0.138 & -0.002 \\
\hline DOC & -0.049 & -0.049 & $-0.408^{b}$ & 0.162 & 0.014 & $0.352^{b}$ \\
\hline TP & -0.003 & 0.032 & -0.192 & $-0.583^{b}$ & $-0.247^{a}$ & 0.191 \\
\hline UV254 & -0.151 & 0.255 & 0.114 & 0.074 & -0.187 & 0.015 \\
\hline SUVA & -0.036 & 0.147 & -0.029 & -0.086 & -0.180 & -0.136 \\
\hline $\mathrm{NO}_{3}{ }^{-}-\mathrm{N}$ & $-0.356^{a}$ & $0.338^{a}$ & 0.307 & -0.274 & -0.097 & 0.027 \\
\hline $\mathrm{SO}_{4}{ }^{2-}$ & 0.014 & -0.207 & $-0.352^{a}$ & -0.035 & -0.136 & -0.071 \\
\hline 2-MIB & 1 & -0.026 & 0.076 & 0.05 & 0.09 & -0.084 \\
\hline Geosmin & & 1 & 0.108 & 0.018 & -0.06 & -0.056 \\
\hline$\beta$-Ionone & & & 1 & $-0.302^{a}$ & -0.109 & -0.077 \\
\hline IPMP & & & & 1 & $0.420^{b}$ & -0.127 \\
\hline
\end{tabular}

concentration showed a positive correlation with $\beta$-cyclocitral, but a negative correlation with $\beta$-ionone. This contradictory result indicates that the exposure concentrations of $\beta$-ionone and $\beta$-cyclocitral produced by $M$. aeruginosa and other algae were not only limited by nutrient salts but also by the natural organic matter (NOM), which has not been reported before.

\section{Co-occurrence of T\&O compounds}

The correlations between odorants were analyzed to confirm the coexistence of T\&Os (Table 3). There was a significant correlation between IPMP and IBMP and negative correlation between IPMP and $\beta$-ionone. The significant correlation between IPMP and IBMP indicates that the co-exposure of IBMP and IPMP in the Taihu Lake was due to the same producers. In general, the producers of IPMP or IBMP were the same; actinomycetes and other soil microorganism in sediment. ${ }^{51}$ Different origins for IPMP and $\beta$-ionone were confirmed by this negative correlation. The origin of $\beta$-ionone was $M$. aeruginosa, ${ }^{52}$ which was not the producer of IPMP. In this study, the dominant T\&O compounds were $\beta$-ionone, $\beta$-cyclocitral, IPMP and IBMP. Based on the abovementioned analysis of co-occurrence, it is proposed that the major algae origins of $\mathrm{T} \& \mathrm{O}$ in the Taihu Lake during the sampling period were $M$. aeruginosa, dead $M$. aeruginosa cells, and other soil microorganisms in sediment were potential microorganism sources. Sediment disturbance and hydraulics in the lake release $\mathrm{T} \& \mathrm{O}$ compounds into the water as important internal sources, which would be very significant in winter. Furthermore, fish and shellfish could absorb T\&O compounds from water into its body and release them sometimes as a mobile source, such as Carassius auratus, Hypophthalmichthys molitrix and Coilia ectenes, which show quite high concentrations of T\&O in their bodies. ${ }^{\mathbf{4 4}}$

\section{Multivariate analysis between T\&O and water quality}

To thoroughly investigate the relationship between the occurrence of T\&O and water quality, PCA and CA were carried out. To examine the suitability of these data for PCA, Kaiser-MeyerOlkin (KMO) and Bartlett's tests were performed. In this study, $\mathrm{KMO}=0.579(>0.5)$ and the significance of Bartlett's test $=$ 0.000 , which indicate that factor analysis might be useful, and there are significant relationships among the variables. The PCA of the 16 water quality parameters and rotated component matrix (Table $\mathrm{S} 3 \dagger$ ) obtained for the variance factor analysis indicate that five factors explained $70.871 \%$ of the total variance. Table S3† also gives the loadings for the five first components and the loading plots are presented in Fig. 5(A). A variable was increasingly well represented by a component as the corresponding value of the loading plots. Almost all variables were well represented by the first three components, group 1, group 2 or group 3.

According to the results of PCA, group 1 was made of geosmin, UV254, TP, TN and nitrate, thus indicating that the occurrence of geosmin was related to nutrition elements and that higher nutrition elements contributed to the occurrence of geosmin. This result is partly consistent with the correlation analysis results (Table 2) and other observed data. ${ }^{18}$ Moreover, other authors also found that geosmin and UV254 were part of the same group using PCA to analyze the occurrence of T\&O. ${ }^{15}$ Group 2 was made of IPMP, IBMP, 2-MIB, $\beta$-ionone and $\beta$ cyclocitral, which indicate that T\&O compounds were one of the major components in all the water parameters. Group 3 was made of DO, temperature, water $\mathrm{pH}$ and sulfate. These water parameters were influenced by each other. The concentration of sulfate was particularly affected by DO, temperature and water $\mathrm{pH} .{ }^{50}$ Based on the above, T\&O compounds were found to be the major micro-pollutants in the Taihu Lake and the nutrition elements were the major factors for geosmin occurrence.

In this study, CA was performed on the measured chemical variables to confirm the associations among these variables. The dendrogram (Fig. 5(B)) shows three different clusters identified as A, B and C. Cluster A is the basic water quality parameter component previously described as group 3 in PCA. The level of dissimilarity detected between clusters B and C 

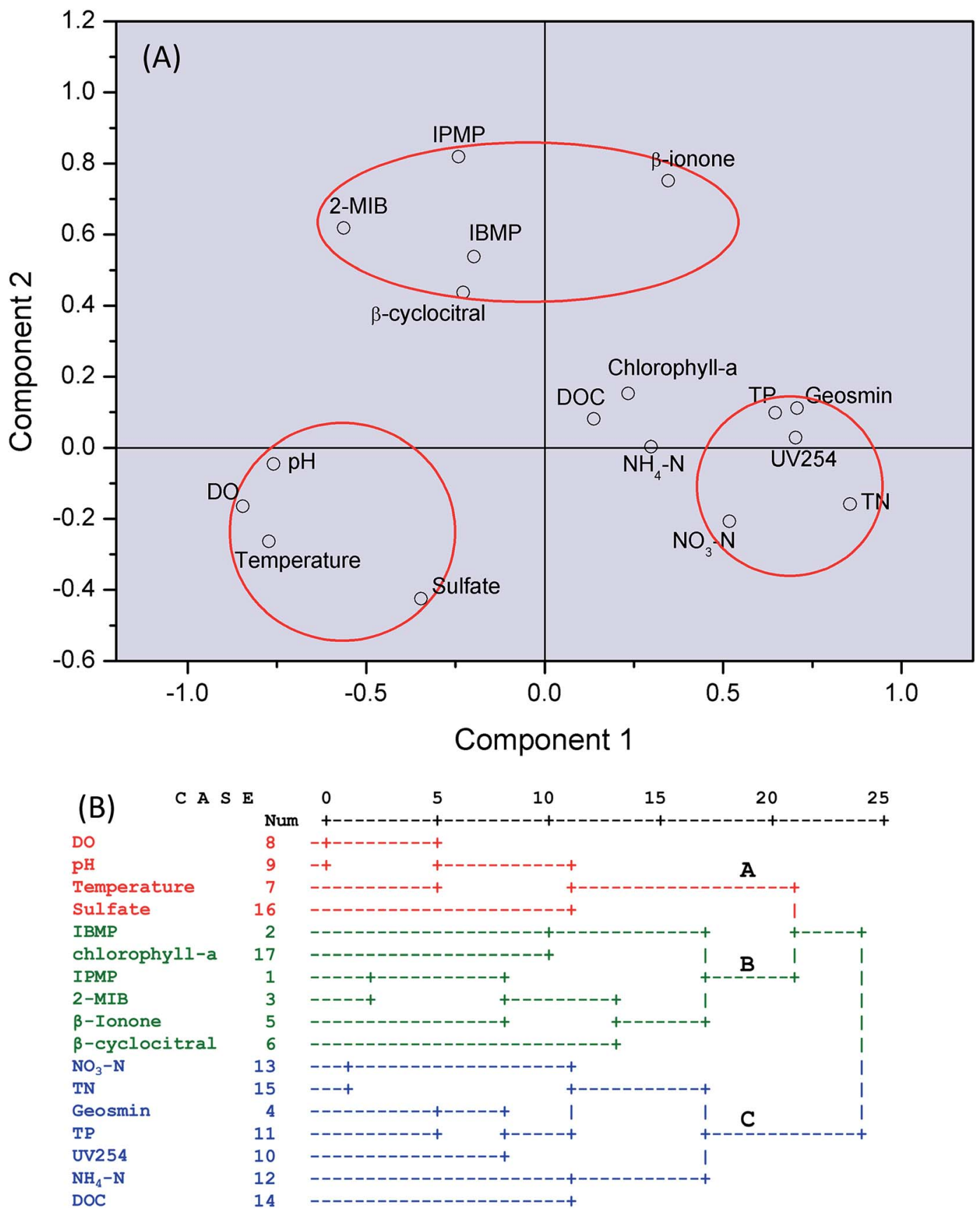

Fig. 5 Variable analyzed by multivariate statistical methods (A) PCA analysis; and (B) cluster analysis.

justifies their association appearing separately in groups 2 and groups 1 in PCA. However, there were some different results for chlorophyll-a, ammonia and DOC obtained from PCA and CA. Chlorophyll-a is an important indicator of algal blooms. Many previous investigations indicate a strong correlation between chlorophyll-a and T\&O compounds. ${ }^{17,45}$ In this study, only IBMP had a correlation with chlorophyll-a $(P<0.05)$. However, chlorophyll-a and five types of T\&O compounds were in cluster B. This is an important supplement for the correlation analysis and PCA, which indicate that algae are still the main producer of T\&O compounds. Ammonia was an important contributor of $\mathrm{TN}$ in the lake and was shown neither in the results of the correlation analysis nor PCA. The presence of DOC and UV254 in cluster $\mathrm{C}$ indicates that UV254 was an important contributor of DOC, and DOC was a major component in the Taihu Lake.

\section{Suggestions for management strategy and purification technology for T\&O occurrence in the Taihu Lake}

The management of water quality and control of T\&O blooms are essential in lakes and reservoirs all over the world. The key points are to improve water quality and eliminate algal blooms. The serious T\&O problems in China can be resolved using the following method and management strategy. It is vital to control the source of pollutants firstly by (1) controlling the input of 
nutrient and organic pollutants using advanced wastewater treatment technology with the function of the removal of nitrogen and phosphate and (2) paying attention to endogenous pollution such as sediments containing nutrient sources, dead microorganism cells and T\&O compounds. ${ }^{53}$ The pollutants mentioned above, if released into freshwater, could cause further algal blooms and T\&O occurrence. Therefore, sediment dredging is very necessary.

The second stage in improving water quality could be (1) managing the breeding of fish such as Hypophthalmichthys molitrix, bighead carp and Carassius auratus cuvieri to uptake algae ${ }^{54,55}$ (2) cultivating aquatic plants to absorb the nutrient sources and eliminate algal bloom $;{ }^{56,57}$ and (3) scheduling lake water utilization to maintain a higher water elevation and mobility to increase the DO level and avoid sediment frost boil.

Third, the present blooming algae should be removed by in situ technology such as using modified soil to eliminate algae $e^{58,59}$ and chemicals. However, it should be pointed out that a nutrient source and T\&O compounds in algal cells might be released as new internal sources during the process of algae removal. ${ }^{53}$

Since many lakes in China are plagued by algal blooms, predicting blooms and $\mathrm{T} \& \mathrm{O}$ occurrence is important in the fourth stage. In general, this can be achieved by remote sensing technology. ${ }^{60,61}$ If algal blooms are predicted accurately, some emergency methods could be used to avoid or eliminate the occurrence of T\&Os. Some mathematical prediction models of $\mathrm{T} \& \mathrm{O}$ occurrence based on regular water quality parameters have been investigated. ${ }^{45,62}$

The regular monitoring of water quality parameters and use of remote sensing technology are worthwhile methods for predicting algae and the occurrence of T\&Os that are derived from them. Finally, if lake water containing T\&O compounds is planned to be used as source water, the application of peroxidation (ozone ${ }^{63}$ or permanganate $^{64}$ ), active carbon adsorption, ozone-biological activated carbon, advanced oxidation processes and membrane filtration should be taken into consideration. ${ }^{65,66}$

\section{Conclusions}

The occurrence of earthy-musty T\&O compounds in the Taihu Lake, which is an important drinking water source, was evaluated in 2009 and 2010. The occurrence of earthy-musty T\&O compounds in 2009 was obviously less than in 2010 and was barely observed. The main contributors changed from $\beta$-ionone and $\beta$-cyclocitral to IPMP and IBMP. The dominant contributors in 2010 reported here are in agreement with the scientific data accumulated on T\&O occurrence in the Taihu Lake.

According to the data obtained from multivariate statistical analysis, earthy-musty T\&O compounds are important micropollutants in the Taihu Lake, and TN, TP and chlorophylla are important water quality parameters influencing the generation of T\&O compounds. IPMP, IBMP and $\beta$-ionone were co-existent odorants, and $M$. aeruginosa, its dead cells and other soil microorganisms in sediment may be the main contributors to T\&O compounds in the Taihu Lake; however, the dominance of IPMP and IBMP was reported for the first time. A four-step strategy for the elimination of the presence of earthy-musty T\&Os in lakes of China is proposed.

\section{Abbreviation}

$\begin{array}{ll}\text { IPMP } & \text { 2-Isopropyl-3-methoxypyrazine } \\ \text { IBMP } & \text { 2-Isobutyl-3-methoxypyrazine } \\ \text { 2-MIB } & \text { 2-Methyloisoborneol } \\ \text { DOC } & \text { Dissolved organic carbon } \\ \mathrm{DO} & \text { Dissolved oxygen } \\ \mathrm{NO}_{3}-\mathrm{N} & \text { Nitrate } \\ \mathrm{T} \& \mathrm{O} & \text { Taste and odor } \\ \mathrm{TN} & \text { Total nitrogen } \\ \mathrm{TP} & \text { Total phosphate } \\ \text { SPME } & \text { Solid-phase micro-extraction }\end{array}$

\section{Acknowledgements}

This study was carried out with the support of the National Natural Science Foundation of China (No. 51578520, 51378063, 41273137 and 51108030), the Beijing Natural Science Foundation (No. L160006 and 8132033) and the Hong Kong Scholars Program. Y. C. Zhang analyzed the data using statistical methods and wrote the manuscript; N. Zhang and B. Xu collected the samples and conducted T\&O analysis; J. Kumirska made many significant revisions to and comments on the manuscript; F. Qi supported the funding for this study and provided significant research assistance.

\section{References}

1 S. Giglio, W. K. W. Chou, H. Ikeda, D. E. Cane and P. T. Monis, Environ. Sci. Technol., 2011, 45, 992-998.

2 J. L. Graham, K. A. Loftin, M. T. Meyer and A. C. Ziegler, Environ. Sci. Technol., 2010, 44, 7361-7368.

3 T. Zhang, L. Li, Y. X. Zuo, Q. Zhou and L. R. Song, J. Water Supply: Res. Technol.-AQUA, 2010, 59, 243-254.

4 Y. X. Zuo, L. Li, Z. X. Wu and L. R. Song, J. Water Supply: Res. Technol.-AQUA, 2009, 58, 552-561.

5 L. Li, N. Wan, N. Gan, B. D. Xia and L. R. Song, Water Sci. Technol., 2007, 55, 43-50.

6 C. P. Dionigi, T. E. Lawlor, J. E. McFarland and P. B. Johnsen, Water Res., 1993, 27, 1615-1618.

7 L. Burgos, M. Lehmann, D. Simon, H. H. R. de Andrade, B. R. R. de Abreu, D. D. Nabinger, I. Grivicich, V. B. Juliano and R. R. Dihl, Sci. Total Environ., 2014, 490, 679-685.

8 A. F. Silva, M. Lehmann and R. R. Dihl, Environ. Sci. Pollut. Res. Int., 2015, 22, 17244-17248.

9 K. Mochida, Biocontrol Sci., 2009, 14, 35-38.

10 X. J. Zhang, C. Chen, J. Q. Ding, A. X. Hou, Y. Li, Z. B. Niu, X. Y. Su, Y. J. Xu and E. A. Laws, J. Hazard. Mater., 2010, 182, 130-135.

11 Y. M. Liu, W. Chen, D. H. Li, Z. B. Huang, Y. W. Shen and Y. D. Liu, J. Environ. Sci., 2011, 23, 575-581.

12 W. D. Qin, L. Y. Yang, X. X. Zhang, Z. Y. Zhang, L. Z. Xu, J. Wu, J. An and Y. P. Wang, Ecotoxicology, 2012, 21, 1495-1503.

13 X. Chuai, X. Chen, L. Yang, J. Zeng, A. Miao and H. Zhao, Int. J. Environ. Sci. Technol., 2012, 9, 503-514. 
14 X. W. Deng, G. D. Liang, J. Chen, M. Qi and P. Xie, J. Chromatogr. A, 2011, 1218, 3791-3798.

15 J. Chen, P. Xie, Z. Ma, Y. Niu, M. Tao, X. Deng and Q. Wang, Sci. Total Environ., 2010, 409, 314-325.

16 Z. Ma, Y. Niu, P. Xie, J. Chen, M. Tao and X. Deng, J. Environ. Sci., 2013, 25, 495-501.

17 Z. Ma, P. Xie, J. Chen, Y. Niu, M. Tao, M. Qi, W. Zhang and X. Deng, Fresenius Environ. Bull., 2013, 22, 95-102.

18 Y. Jiang, B. Cheng, M. Liu and Y. Nie, Bull. Environ. Contam. Toxicol., 2016, 96, 186-191.

19 J. W. Yu, Y. M. Zhao, M. Yang, T.-F. Lin, Z. H. Guo, J. N. Gu, S. Li and W. Han, J. Water Supply: Res. Technol.-AQUA, 2009, 58, 587-594.

20 J. Ebina, T. Tsutsui and T. Shirai, Water Res., 1983, 17, 17211726.

21 F. Juttner and S. B. Watson, Appl. Environ. Microbiol., 2007, 73, 4395-4406.

22 F. Juttner, S. B. Watson, E. von Elert and O. Koster, J. Chem. Ecol., 2010, 36, 1387-1397.

23 E. Agus, M. H. Lim, L. Zhang and D. L. Sedlak, Environ. Sci. Technol., 2011, 45, 9347-9355.

24 J. Parinet, M. J. Rodriguez and J. Serodes, Water Res., 2010, 44, 5847-5856.

25 S. B. Watson, Phycologia, 2003, 42, 332-350.

26 F. Juttner, Water Sci. Technol., 1983, 15, 11.

27 E. Cotsaris, A. Bruchet, J. Mallevialle and D. B. Bursill, Water Sci. Technol., 1995, 31, 251-258.

28 A. B. Santos, A. S. Fernandes, R. Wagner, E. Jacob-Lopes and L. Q. Zepka, J. Appl. Phycol., 2016, 28, 1561-1570.

29 A. Peter, O. Köster, A. Schildknecht and U. von Gunten, Water Res., 2009, 43, 2191-2200.

30 X. Yang, P. Xie, Y. Yu, H. Shen, X. Deng, Z. Ma, P. Wang, M. Tao and Y. Niu, J. Environ. Sci., 2015, 31, 38-43.

31 K. Tomita, M. Hasegawa, S. Arii, K. Tsuji, B. Bober and K.-I. Harada, Environ. Sci. Pollut. Res. Int., 2016, 23, 1199812006.

32 T. Kajiwara, K. Matsui, Y. Akakabe, T. Murakawa and C. Arai, J. Appl. Phycol., 2006, 18, 413-422.

33 S. E. Jensen, C. L. Anders, L. J. Goatcher, T. Perley, S. Kenefick and S. E. Hrudey, Water Res., 1994, 28, 13931401.

34 B. Zaitlin and S. B. Watson, Water Res., 2006, 40, 1741-1753.

35 J. L. Smith, G. L. Boyer and P. V. Zimba, Aquaculture, 2008, 280, 5-20.

36 M. Su, J. Yu, J. Zhang, H. Chen, W. An, R. D. Vogt, T. Andersen, D. Jia, J. Wang and M. Yang, Water Res., 2015, 68, 444-453.

37 Q. Wang, Y. A. Niu, P. Xie, J. Chen, Z. M. Ma, M. Tao, M. Qi, L. Y. Wu and L. G. Guo, Sci. World J., 2010, 10, 1795-1809.

38 Y. Niu, H. Shen, J. Chen, P. Xie, X. Yang, M. Tao, Z. M. Ma and M. Qi, Water Res., 2011, 45, 4169-4182.

39 Y. Xu, W. Li, W. W. Zhong and Z. Y. Yuan, Acta Ecol. Sin., 1999, 19, 212-216.

40 Y. Pan, L. Xu, W. Cao, S. Yin, Z. Wang and Q. Zhou, Water Sci. Technol., 2009, 59, 1185-1194.
41 K. J. Zhang, T. Q. Zhang, Y. Deng, N. Y. Gao and Y. L. Yang, J. Water Supply: Res. Technol.-AQUA, 2015, 64, 824-831.

42 D. Sun, J. Yu, W. An, M. Yang, G. Chen and S. Zhang, J. Environ. Sci., 2013, 25, 460-465.

43 X. Chen, Q. Luo, D. Wang, J. Gao, Z. Wei, Z. Wang, H. Zhou and A. Mazumder, Environ. Pollut., 2015, 206, 64-72.

44 Y. Jiang, P. Xie and Y. Nie, Bull. Environ. Contam. Toxicol., 2014, 93, 643-648.

45 M. Qi, J. Chen, X. Sun, X. Deng, Y. Niu and P. Xie, PLoS One, 2012, 7, e51976.

46 Z. Ding, S. Peng, Y. Jin, Z. Xuan, X. Chen and L. Yin, J. Anal. Methods Chem., 2014, 743924.

47 X.-J. Zhang, C. Chen, J.-Q. Ding, A. Hou, Y. Li, Z.-B. Niu, X.-Y. Su, Y.-J. Xu and E. A. Laws, J. Hazard. Mater., 2010, 182, 130-135.

48 X. Wang, M. Sun, M. Xie, M. Liu, L. Luo, P. Li and F. Kong, Water Res., 2013, 47, 5659-5669.

49 X. Wang, M. Sun, J. Wang, L. Yang, L. Luo, P. Li and F. Kong, Microb. Ecol., 2012, 64, 986-999.

50 D. Yu, P. Xie, C. Zeng, L. Xie and J. Chen, Ecol. Eng., 2016, 87, 246-253.

51 Y. X. Zuo, L. Li, T. Zhang, L. L. Zheng, G. Y. Dai, L. M. Liu and L. R. Song, Water Res., 2010, 44, 6085-6094.

52 W. J. Huang, C. H. Lai and Y. L. Cheng, Sci. Total Environ., 2007, 377, 214-223.

53 C. Shao, L. Li, S.-L. Yu, L.-A. Hou, F. Yang, Q. Yin and Q. Qi, Zhongguo Huanjing Kexue, 2014, 34, 2328-2333.

54 J. Feng, F. Li, X. Zhou, C. Xu and F. Fang, Ecol. Eng., 2016, 94, 315-319.

55 G. Liu, Z. Liu, J. M. Smoak and B. Gu, Quat. Int., 2015, 355, 188-193.

$56 \mathrm{H}$. E. Keizer-Vlek, P. F. M. Verdonschot, R. C. M. Verdonschot and D. Dekkers, Ecol. Eng., 2014, 73, 684-690.

57 R. Mao, H.-M. Chen, X.-H. Zhang, F.-X. Shi and C.-C. Song, Sci. Total Environ., 2016, 559, 1-6.

58 G. Pan, H. Zou, H. Chen and X. Yuan, Environ. Pollut., 2006, 141, 206-212.

59 H. Zou, G. Pan, H. Chen and X. Yuan, Environ. Pollut., 2006, 141, 201-205.

60 R. M. Kudela, S. L. Palacios, D. C. Austerberry, E. K. Accorsi, L. S. Guild and J. Torres-Perez, Remote Sens. Environ., 2015, 167, 196-205.

61 M. W. Matthews, S. Bernard and K. Winter, Remote Sens. Environ., 2010, 114, 2070-2087.

62 A. R. Dzialowski, V. H. Smith, D. G. Huggins, F. deNoyelles, N.-C. Lim, D. S. Baker and J. H. Beury, Water Res., 2009, 43, 2829-2840.

63 F. Qi, B. Xu, Z. Chen, J. Ma, D. Sun and L. Zhang, Water Environ. Res., 2009, 81, 2411-2419.

64 P. Xie, J. Ma, J. Fang, Y. Guan, S. Yue, X. Li and L. Chen, Environ. Sci. Technol., 2013, 47, 14051-14061.

65 M. Antonopoulou, E. Evgenidou, D. Lambropoulou and I. Konstantinou, Water Res., 2014, 53, 215-234.

66 K. Zoschke, N. Dietrich, H. Börnick and E. Worch, Water Res., 2012, 46, 5365-5373. 